\title{
The essential implications of gender in human behavioral endocrinology studies
}

\author{
Steven J. Stanton ${ }^{1,2 *}$ \\ Department of Psychology and Neuroscience, Duke University, Durham, NC, USA \\ 2 Center for Cognitive Neuroscience, Duke University, Durham, NC, USA \\ *Correspondence: steven.stanton@duke.edu
}

\section{A commentary on}

Power posing: brief nonverbal displays affect neuroendocrine levels and risk tolerance

by Carney, D. R., Cuddy, A. J. C., and Yap, A. J. (2010). Psychol. Sci.21, 1363-1368. doi: $10.1177 / 0956797610383437$

Carney et al. (2010) recently published a study in which they examined the effect of assuming "high- and low-power" body postures on changes in testosterone levels in men and women. To do so, they randomly assigned participants to two groups (highpower and low-power), and then placed them in two successive 1-min poses appropriate for their group. They reported that "high-power" poses produced testosterone increases in participants and "low-power" poses produced testosterone decrements, while collapsing over gender in their analyses. This study tested an important hypothesis regarding the effects of dominance posturing on endocrine changes that may be critical precursors to dominance competition, in which dominance posturing could lead to pre-competition changes in testosterone that influence the impending dominance competition (Mazur, 1985; Salvador et al., 2003; Gleason et al., 2009; Edwards and Kurlander, 2010). While Carney et al. (2010) asked an important research question, there are a number of methodological and analytical factors regarding gender and testosterone that must be considered in greater detail before their data can be fully understood and used to motivate future research.

\section{GENDER DIFFERENCES IN TESTOSTERONE RESPONSES TO DOMINANCE SITUATIONS}

Before commenting on specific aspects of the work of Carney et al. (2010), it is informative and relevant to consider gender differences in testosterone responses to dominance situ- ations (e.g., sports, laboratory competitions) found in past studies. Generally, across many studies, men's testosterone levels change in response to dominance competitions by rising after a dominance victory and falling after a defeat (reviewed in Mazur and Booth, 1998; Archer, 2006; e.g., Stanton et al., 2009). Although, recent studies have also suggested that individual differences and context are relevant in accurately predicting men's testosterone responses (e.g., Schultheiss et al., 2005; Carre, 2009) and others have shown null results of competition (e.g., Carre et al., 2009). In contrast, women do not have differential testosterone responses to winning or losing a dominance contest (Mazur and Booth, 1998; Archer, 2006; Stanton and Schultheiss, 2007), but a single recent study has challenged this conclusion (Oliveira et al., 2009).

The commonly observed gender difference in testosterone responses to dominance situations is likely due to the different source glands for testosterone in men and women. In men, the vast majority of testosterone comes from the testes (and the adrenal glands to a lesser extent). In women, testosterone is principally released by the adrenal glands (and the ovaries to a lesser extent). This difference in testosterone source glands makes symmetrical testosterone responses in both genders unlikely ${ }^{1}$. Even if the adrenals were the source of testosterone change in both genders, one would then expect cortisol changes (also produced by the adrenals) to be in the same direction as testosterone changes. Yet, Carney et al. (2010) report that cortisol changes in the same participants moved in the opposing direction to testo-

\footnotetext{
${ }^{1}$ Another potential confound: Carney et al. (2010) provided no information on oral contraceptive use by the female participants, which significantly alters endogenous testosterone levels (e.g., Schultheiss et al., 2005) and may alter hormone $\times$ behavior associations (Josephs, 2009; Stanton and Edelstein, 2009).
}

sterone changes, such that "high-power" poses were associated with decrements in cortisol and "low-power" poses were associated with increases in cortisol ${ }^{2}$. This suggests that the testosterone changes were not driven by the adrenals and makes it less likely that the testosterone responses would have been the same in each gender since the adrenals are the main testosterone-producing gland shared between the genders.

It is notable that Carney et al. (2010) do not discuss the gender-specific mechanisms of testosterone production and release or the empirical history of gender differences in testosterone responses. The gender difference in testosterone source glands and lack of prior positive findings in women do not mandate that testosterone responses to "power poses" would also differ between the genders, but greater consideration of the effects of gender are essential due to these fundamental neuroendocrine differences between the genders.

\section{COLLAPSING OVER GENDER}

Carney et al. (2010) collapsed over gender in all testosterone analyses. Testosterone conforms to a bimodal distribution when including both genders (see Figure $\mathbf{1}^{3}$; Sapienza et al., 2009). Raw testosterone cannot be considered a normally distributed dependent or independent variable

${ }^{2}$ Mean cortisol levels for all participants were reported as $0.16 \mathrm{ng} / \mathrm{mL}$ pre-posing and $0.12 \mathrm{ng} / \mathrm{mL}$ post-posing, thus showing that for all participants there was an average decrease of $0.04 \mathrm{ng} / \mathrm{mL}$ from pre- to postposing, regardless of condition. Yet, Figure 4 of Carney et al. (2010) shows that low-power posers had mean cortisol increases of roughly $0.025 \mathrm{ng} / \mathrm{mL}$ and highpower posers had mean cortisol decreases of roughly $0.03 \mathrm{ng} / \mathrm{mL}$. It is unclear given the data in Figure 4 how the overall cortisol change for all participants could have been a decrease of $0.04 \mathrm{ng} / \mathrm{mL}$.

${ }^{3}$ The University of Michigan's Institutional Review Board and Duke University's Institutional Review Board approved all of the experiments in which the saliva samples were collected and testosterone was assayed. 


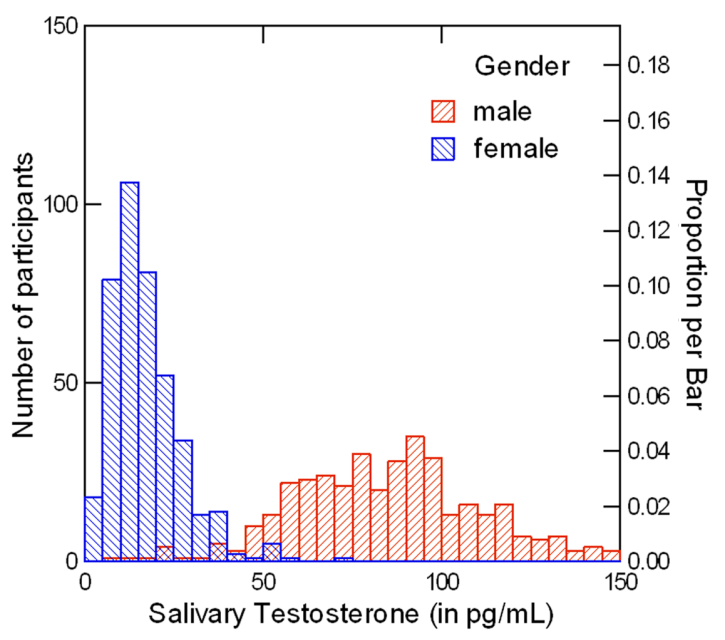

FIGURE 1 | Shown is a depiction of the bimodal distribution of raw, baseline salivary testosterone values (in $\mathrm{pg} / \mathrm{mL}$ ) when including both $\operatorname{men}(N=360)$ and women $(N=407)$. All saliva samples were collected and assayed by the present author using radioimmunoassay (Schultheiss and Stanton, 2009). The displayed testosterone data were aggregated from several past studies by the author, and for graphical purposes only, exclude eight male participants with testosterone levels between 150 and $230 \mathrm{pg} / \mathrm{mL}$.

when including both genders. Thus, Carney et al. (2010) violated a basic assumption of the statistical analyses that they reported, because they used raw testosterone from pre- and post-power posing as independent and dependent variables, respectively, with all subjects (male and female) included.

Additionally, Carney et al. (2010) excluded a single subject (presumably of the 16 men) for having testosterone levels above 3 SD from the mean. But, was this the mean and SD for all subjects? Such exclusions should only occur when computing means and SDs within each sex. This is because when considering the exclusion of high-testosterone cases (likely men), the mean and SD for the whole sample (including men and women) would be artificially low and small, respectively, as compared to the mean and SD for just men. Using the whole sample mean and SD would make it easy to exclude a hightestosterone male subject that is not really an outlier within their own sex, which is what is most important to identify for testosterone analyses. As an additional cautionary note, using the mean and SD for the whole sample would also mean that a woman who is a significant high outlier would likely not be excluded, since she could easily fall within the normal range when including men. The same is true for low values in men, such that a man with a very low testosterone level would be hard to identify because he could fall within the normal range when including women.

In their statistical analyses, the Carney et al. (2010) reported "participant sex was included as a covariate in all analyses.” But, they did not report whether or not participant sex accounted for a significant portion of the variance in any analyses, which leaves open the possibility that the effects are driven principally by one sex, or that the sexes might have exhibited divergent patterns of testosterone response. Ideally for such analyses, it would be best to report the effect size and $p$-value for the main effect of gender as well as a potential gender $\times$ power pose condition interaction. While the authors use residual change in their statistical tests of testosterone change (which is a valid, well-chosen technique) and include gender as a covariate, again, the bimodal distribution of raw testosterone is a statistical issue, since raw postcompetition testosterone is their dependent variable and raw pre-competition testosterone is their covariate, both collapsing over gender. Additionally, Carney et al. (2010) had a small sample size for a human behavioral endocrinology study $(N=42)$ that was predominantly composed of women $(N=26)$, which makes the reported effects of power posing on testosterone change even more surprising given the common lack of testosterone changes in women as a func- tion of dominance situations that was noted above.

\section{MAGNITUDE OF TESTOSTERONE CHANGE}

Men tend to have baseline testosterone levels three to seven times greater than women on average (Dabbs, 1990; Liening et al., 2010). Despite reporting that testosterone levels were significantly higher in men than women via a $t$-test, Carney et al. (2010) do not report the mean testosterone levels separately for each gender at baseline or postmanipulation, which are essential for the interpretation of magnitude of testosterone change. Without reporting the testosterone changes separately for each gender, we simply cannot deduce the real magnitude of the effect for men and women, since their baseline testosterone levels are so different.

In conclusion, Carney et al. (2010) used a novel manipulation to ask an important question, but the degree to which their findings can be fully understood and implemented into future research is questionable without more complete analyses.

\section{REFERENCES}

Archer, J. (2006). Testosterone and human aggression: an evaluation of the challenge hypothesis. Neurosci. Biobehav. Rev. 30, 319-345.

Carney, D. R., Cuddy, A. J. C., and Yap, A. J. (2010). Power posing: brief nonverbal displays affect neuroendocrine levels and risk tolerance. Psychol. Sci. 21, 1363-1368.

Carre, J. M. (2009). No place like home: testosterone responses to victory depend on game location. Am. J. Hum. Biol. 21, 392-394.

Carre, J.M., Putnam, S. K., and McCormick, C. M. (2009). Testosterone responses to competition predict future aggressive behaviour at a cost to reward in men. Psychoneuroendocrinology 34, 561-570.

Dabbs, J. M. Jr. (1990). Salivary testosterone measurements: reliability across hours, days, and weeks. Physiol. Behav. 48, 83-86.

Edwards, D. A., and Kurlander, L. S. (2010). Women's intercollegiate volleyball and tennis: effects of warmup, competition, and practice on saliva levels of cortisol and testosterone. Horm. Behav. 58, 606-613.

Gleason, E. D., Fuxjager, M.J., Oyegbile, T.O., and Marler, C. A. (2009). Testosterone release and social context: when it occurs and why. Front. Neuroendocrinol. 30, 460-469.

Josephs, R. A. (2009). Moving beyond dichotomies in research on oral contraceptives: a comment on Edwards and O'Neal. Horm. Behav. 56, 193-194.

Liening, S.H., Stanton, S. J., Saini, E. K., and Schultheiss, O.C. (2010). Salivary testosterone, cortisol, and progesterone: two-week stability, interhormone correlations, and effects of time of day, menstrual cycle, and oral contraceptive use on steroid hormone levels. Physiol. Behav. 99, 8-16.

Mazur, A. (1985). A biosocial model of status in face-toface primate groups. Soc. Forces 64, 377. 
Mazur,A., and Booth, A. (1998). Testosterone and dominance in men. Behav. Brain Sci. 21, 353-363; discussion 363-397.

Oliveira, T., Gouveia, M. J., and Oliveira, R. F. (2009). Testosterone responsiveness to winning and losing experiences in female soccer players. Psychoneuroendocrinology 34, 1056-1064.

Salvador, A., Suay, F., Gonzalez-Bono, E., and Serrano, M. A. (2003). Anticipatory cortisol, testosterone and psychological responses to judo competition in young men. Psychoneuroendocrinology 28, 364-375.

Sapienza, P., Zingales, L., and Maestripieri, D. (2009). Gender differences in financial risk aversion and career choices are affected by testosterone. Proc. Natl. Acad. Sci. U.S.A. 106, 15268-15273.
Schultheiss, O. C., and Stanton, S. J. (2009). “Assessment of salivary hormones," in Methods in Social Neuroscience, eds E. Harmon-Jones and J. S. Beer (New York, NY: Guilford Press), 17-44.

Schultheiss, O. C., Wirth, M. M., Torges, C. M., Pang, J. S., Villacorta, M. A., and Welsh, K. M. (2005). Effects of implicit power motivation on men's and women's implicit learning and testosterone changes after social victory or defeat. J. Pers. Soc. Psychol. 88, 174-188.

Stanton, S. J., Beehner, J. C., Saini, E. K., Kuhn, C. M., and LaBar, K. S. (2009). Dominance, politics, and physiology: voters' testosterone changes on the night of the 2008 United States Presidential election. PLoS ONE4, e7543. doi: 10.1371/journal.pone.0007543

Stanton, S. J., and Edelstein, R. S. (2009). The physiology of women's power motive: implicit power motivation is positively associated with estradiol levels in women. J. Res. Pers. 43, 1109-1113.

Stanton, S. J., and Schultheiss, O. C. (2007). Basal and dynamic relationships between implicit power motivation and estradiol in women. Horm. Behav. 52,571-580.

Received: 28 September 2010; accepted: 21 February 2011; published online: 08 March 2011.

Citation: Stanton SJ (2011) The essential implications of gender in human behavioral endocrinology studies. Front. Behav. Neurosci. 5:9. doi: 10.3389/fnbeh.2011.00009

Copyright (c) 2011 Stanton. This is an open-access article subject to an exclusive license agreement between the authors and Frontiers Media SA, which permits unrestricted use, distribution, and reproduction in any medium, provided the original authors and source are credited. 